PRAXIS

ecucativa

Universidad Nacional de La Pampa

Facultad de Ciencias Humanas

Instituto de Ciencias de la Educación

para la investigación interdisciplinaria

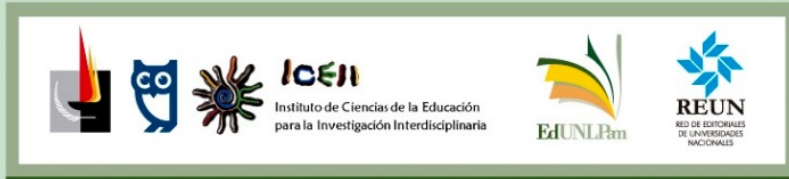

ISSN 2313-934X

SANTA ROSA, LA PAMPA, ARGENTINA

Correo electrónico: iceii@humanas.unlpam.edu.ar

Disponible en https://cerac.unlpam.edu.ar/index.php/praxis

Apropiación de TIC en docentes de la educación superior: una mirada desde los contenidos digitales. Artículo de Gloria María ÁlvarezCadavid y César Augusto González-Manosalva. Praxis educativa, Vol. 26, No 1 enero - abril 2022. E - ISSN 2313-934X. pp. 1-25. https://dx.doi.org/10.19137/praxiseducativa-2022-260104

Esta obra se publica bajo Licencia Creative Commons 4.0 Internacional CC BY-NC-SA Atribución, No Comercial, Compartir igual

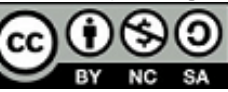

\title{
Apropiación de TIC en docentes de la educación superior: una mirada desde los contenidos digitales
}

Appropriation of ICT in higher education teachers: a view from digital contents

Apropriação de TIC em professores do ensino superior: um olhar desde os conteúdos

digitais

\section{Gloria María Álvarez-Cadavid}

Universidad Pontificia Bolivariana, Colombia

gloria.alvarez@upb.edu.co

ORCID 0000-0002-7773-7372

\section{César Augusto González-Manosalva}

Universidad Pontificia Bolivariana, Colombia

cesar.gonzalez@upb.edu.co

ORCID 0000-0002-1401-5524

Recibido: 2021-03-03 | Revisado: 2021-06-09 | Aceptado: 2021-08-09 


\section{Resumen}

Se brinda una mirada a la apropiación de Tecnologías de Información y Comunicación (TIC) desde los contenidos digitales. La metodología se orientó a identificar tendencias de uso de TIC mediante la aplicación de un instrumento tipo encuesta, respondido por 404 docentes. Se consultaron las prácticas en el uso de TIC, los criterios para la elección de contenidos, las estrategias metodológicas y la formación en el uso y elaboración de contenidos. Los resultados evidencian una brecha discursiva entre la importancia otorgada a las TIC y las prácticas docentes, se observó un uso de las mismas herramientas en las dos últimas décadas y poca implementación de proyectos de innovación educativa en docencia. Igualmente, las TIC se asumen más como apoyo a la presencialidad y los docentes son más consumidores que productores de contenidos. Lo anterior contrasta con la aceleración de la apropiación de TIC ocasionada por la pandemia del Covid- 19.

Palabras clave: TIC; Tecnología educacional; Recursos informacionales; Competencias del docente; Enseñanza superior

\section{Abstract}

This paper provides a view on the appropriation of Information and Communication Technologies (ICT's) from the perspective of digital contents. The methodology was aimed at identifying trends in the use of ICT'S, through the application of a survey type instrument (Likert), answered by 404 teachers. Practices in the use of ICT's, criteria for choosing content, methodological strategies and training in the use and development of content were consulted. The results show a discursive gap between the importance given to ICT's and the teaching practices. It was identified that the respondents have been using the same tools for the past two decades. Besides, there is little implementation of educational innovation projects in their teaching. Likewise, ICT's are assumed as a support for face-to-face teaching and teachers are more consumers than content producers. These findings contrast with the acceleration of the appropriation of ICT's caused by the Covid-19 pandemic.

Keywords: ICT's, Educational technology; educational resources; teacher qualifications; higher Education

\section{Resumo}

Dá-se um olhar à apropriação de Tecnologias de Informação e Comunicação (TIC) desde os conteúdos digitais. A metodologia orientou-se a identificar tendências de uso de TIC mediante a aplicação de um instrumento tipo inquérito, respondido por 404 professores. Foram consultadas as práticas no uso de TIC, os critérios para a eleição de conteúdos, as estratégias metodológicas e a formação no uso e elaboração de conteúdos. Os resultados evidenciam uma lacuna discursiva entre a importância atribuída às TIC e as práticas pedagógicas, observou-se um uso das mesmas ferramentas nas duas últimas décadas e pouca implementação de projetos de inovação educativa no ensino. Igualmente, as TIC assumem-se mais como apoio do presencial e os professores são mais consumidores que produtores de conteúdos. 0 anterior contrasta com a aceleração da apropriação de TIC gerada pela pandemia do Covid-19.

Palavras-chave: TIC; Tecnologia educacional; recursos informativos; competências do professor; ensino superior. 


\section{Introducción}

Cada tecnología y su uso ha develado el desarrollo sociotécnico de la época. Hoy, en la llamada sociedad del conocimiento, las mediaciones de las tecnologías digitales tienen una presencia preponderante en todos los escenarios de la vida cotidiana y es por ello que comprender estos vínculos se ha tornado en una vía para entender las transformaciones sociales que hoy enfrentamos a un ritmo cada vez más acelerado y que la pandemia del COVID-19 se ha encargado de catalizar.

Uno de los acercamientos conceptuales y metodológicos, para comprender los vínculos del hombre con su medio, es el estudio de la Apropiación Social de las Tecnologías (AST). Este campo de conocimiento toma fuerza teórica desde la primera mitad del siglo XX y ha sido asumido por buena parte del discurso de las políticas públicas de ciencia y tecnología, horizonte que, por ejemplo, en Colombia, se puede rastrear desde la década de los 80 del siglo anterior (Escobar-Ortiz, 2017). Si bien, propende por una divulgación, democratización y generación de un pensamiento crítico frente al conocimiento científico, no hay evidencias claras, desde este horizonte, que permitan tener indicadores o mediciones precisas del mismo.

Así, la apropiación social de tecnologías es un tema que ha estado posicionado más como discurso en políticas públicas que como una realidad clara. Sin embargo, la investigación sobre la apropiación de tecnologías ha adquirido cada vez más relevancia y especificidad, en especial desde la aparición de Internet, y uno de los campos donde ha crecido más el interés por su estudio es el educativo. De la misma manera, este campo de estudio ha lastrado con una dupla indiferenciada entre usos y apropiación que, en muchos casos, no permite establecer su diferencia, ni la relación entre uno y otro concepto, pues no todo uso implica un proceso de apropiación, pero toda apropiación sí implica unas prácticas de uso concretas (Giraldo-Ramírez y Alvarez-Cadavid, 2009).

Este texto toma los contenidos educativos digitales y el uso general de las TIC en la docencia como el escenario para entender ese vínculo que cada profesor establece con la tecnología en sus prácticas pedagógicas concretas y aportar a la comprensión de los procesos de apropiación de TIC en la educación. Se asume, entonces, la apropiación como un trayecto con surcos que se recorren de manera individual y colectiva; que requieren rutinas y estabilización en el tiempo; que demandan procesos reflexivos de la acción. Tal como lo plantean Cabello y López (2017), la apropiación es un proceso susceptible de ser comprendido que, a la vez, permite comprender. Es por ello que nos preguntamos: ¿de qué manera los contenidos digitales educativos y las prácticas de uso de TIC nos permiten comprender la apropiación?

La investigación realizada se hizo bajo un doble abordaje: el primero, desde algunas historias particulares donde se sistematizó la práctica docente referida a los contenidos en distintas áreas por docentes concretos; el segundo abordaje, una indagación estadística a un grupo de 400 docentes es el que aquí se presenta y nos permite hacer una lectura de tendencias de la apropiación, cuyo valor son las diversas paradas que los resultados permiten hacer a manera de tendencia o puntos en tensión para reflexionar sobre los principales elementos que pueden 
configurar un trayecto de apropiación social de las TIC en un escenario educativo de nivel superior y que merece hoy ser revisado.

\section{Los contenidos educativos digitales: una opción para leer los procesos de apropiación de TIC en docentes universitarios}

La apropiación de Tecnologías de Información y Comunicación (TIC), en el terreno docente, debe tener en cuenta dos dimensiones: por un lado, los saberes que se enseñan, los cuales se han transformado por vía del desarrollo tecnológico, un ejemplo de esto sería hoy el conocimiento médico a partir del cual las prácticas y procedimientos actuales son muy distintos a los de hace 50 años y esto podría decirse, prácticamente, de todos los campos de conocimiento. Por otro lado, las prácticas comunicativas se han ampliado y, hoy, se cuenta con sistemas de comunicación virtual, material multimedia, redes sociales y un acceso a gran variedad de fuentes de información sobre el conocimiento que minuto a minuto se produce en el mundo, en cualquier campo del saber.

Lo anterior plantea que tanto los saberes que enseñamos como las formas en que investigamos y comunicamos dicho conocimiento se han transformado con la tecnología. Sin embargo, en el terreno de la enseñanza y el aprendizaje, la apropiación de TIC tiene otros ritmos y características, cuyo estudio permite comprender no solo el uso per se de estas, sino las concepciones que tenemos del saber y la forma en que lo enseñamos. En este sentido, la pandemia ha dado un vuelco a la educación que venía en procesos más lentos de transformación.

Los contenidos digitales educativos son un escenario idóneo para entender esa vinculación entre el saber, la tecnología y la comunicación. Los contenidos reúnen una materialidad que los objetualiza, les otorga un carácter simbólico que los representa y que se asocia a las concepciones del saber y a las concepciones pedagógicas respecto a cómo se enseña dicho saber.

Consideramos que es importante, aunque sea de forma breve, dejar claro, en este texto, qué entendemos por contenidos digitales educativos, al menos en términos del alcance que pueden tener sus distintas nominaciones. Desde el punto de vista pedagógico, un contenido hace parte de la conocida triada: docente, estudiante y contenido (saber). En ese sentido, un contenido tiene una función mediadora en el aprendizaje, donde confluyen tanto las concepciones de cada docente, frente al saber y su enseñanza, como las concepciones del estudiantado, referidas a los conocimientos previos sobre el tema y sobre la manera o el estilo en que aprende.

Además, de esta perspectiva mediacional, es importante mirar el alcance que desde las múltiples nominaciones se les da a los contenidos educativos digitales. En la literatura, se pueden encontrar referencias que denominan contenido desde un documento digital de apoyo a la docencia presencial hasta la propuesta de un curso totalmente virtual. En ese variado panorama, es común que se hable indistintamente de contenidos, recursos, material didáctico, entre otros. Por eso, proponemos hacer una distinción entre esta terminología, en especial desde la intención educativa con la que se realizan y se usan. Cuando se habla de contenidos, no solo se alude a un 
objeto material que porta una información, sino que además implica concepciones, estrategias, actividades y acciones de aprendizaje. En síntesis, se puede afirmar que hay dos grandes tipologías de contenidos:

- Contenido educativo digital o recurso educativo digital: nominación global o genérica que comprende todo aquel material elaborado con intención educativa y cuyos fines fueron pensados para los procesos de enseñanza y aprendizaje. En esta clasificación, están los Ilamados "Objetos Virtuales de Aprendizaje" (OVA) y los "Recursos Educativos Digitales Abiertos" (REDA o REA), cuyas características de accesibilidad (abierta o no), modularidad, interoperabilidad, estandarización y reutilización en diversos contextos los hacen una producción muy específica para el campo educativo.

- Material y recurso didáctico: son aquellos que no fueron creados con una intención pedagógica específica, ni pensados para el contexto educativo. Sin embargo, el uso que se hace de ellos sí es educativo; una película de cine, un video musical, una entrevista, una imagen puede convertirse en un material didáctico en virtud del uso que se le da. De acuerdo con lo anterior y a partir de la revisión de literatura, se pueden establecer varias tendencias en el tema de los contenidos digitales educativos en las dos últimas décadas. Desde el inicio del siglo XXI, la construcción de OVA y REA toma fuerza con las propuestas de David Wiley (2002) en el marco del diseño instruccional. Para este momento, los puntos fundamentales en la temática eran la disponibilidad (acceso) y reutilización. Se comenzaron a crear repositorios y bancos de objetos virtuales internacionales como Merlot' o, en Colombia, para el 2004, se crea el portal educativo Colombia Aprende y se lanza la estrategia del Banco Nacional de Objetos de Aprendizaje, desde la cual se insistió en la importancia de la catalogación con metadatos para estandarizarlos, hacerlos accesibles y poblar de recursos este sitio (Colombia Aprende). Posteriormente, del 2006 al 2009, se crea, en Colombia, la red de bancos de objetos de aprendizaje, que tuvo como estrategia la catalogación de OVA, con el fin de que existiera consenso sobre sus características y donde las universidades integraran sus repositorios a una red nacional.

A partir de la primera década del siglo XXI, cobra fuerza el tema del acceso abierto y la propiedad intelectual de los contenidos, no solo educativos, sino informativos y de divulgación científica. Sin embargo, hoy no es tan claro qué ha pasado con este tema, en especial en cuanto al uso o reutilización, pues el tema de la evaluación del uso en contenidos en repositorios aún es muy incipiente, costoso y complejo, con lo cual no es clara la calidad de los recursos disponibles (Sanz et al., 2011).

Por ejemplo, en Colombia, se puede tener un rastreo desde la documentación oficial del Ministerio de Educación Nacional (MEN) hasta el 2012, fecha en la que se hizo un balance de los logros sobre los OVA referida a las estrategias para fomentar su realización como los programas formativos para docentes y las redes de repositorios. Desde esa misma fecha, hay un giro hacia los contenidos abiertos (MEN, 2012) y, en 2014 y 2015, el MEN lanza la estrategia de REDA, enfocada a fortalecer los repositorios en la lógica del acceso abierto. Sin embargo, la información encontrada luego del 2015 hasta la fecha está muy fraccionada y dispersa para el tema concreto de los 
contenidos, pues se encuentran observatorios con indicadores generales para la innovación educativa, en donde el tema de los contenidos es uno de ellos. En este sentido, a pesar de que la literatura es abundante, no se encontraron documentos oficiales, por lo menos en el contexto colombiano, que dieran un panorama sobre lo que ha pasado con el tema de los contenidos digitales abiertos, los repositorios y la formación de docentes.

En el marco de esta investigación, pudimos constatar que, en la institución objeto de estudio, hay un uso muy bajo del material que producen y comparten los docentes en el repositorio institucional.i Se puede afirmar que, si bien hay mucho material, poco se consulta. Incluso, se prefiere crear material nuevo sin tener una idea clara de lo que ya existe, práctica que aumenta el número de objetos, pero no así el uso de los mismos. Bajo esta lógica de la producción de contenidos, pareciera que el ciclo de vida de un recurso finaliza al ser almacenado (Leal, 2015).

Hoy, el discurso internacional sobre los contenidos digitales se ha desplazado hacia la creación de situaciones o experiencias de aprendizaje, desde una perspectiva comunicativa, ubicada en lo que se denomina ecología del diseño de recursos (Gros y López, 2016), donde se plantea la participación del estudiantado como cocreadores de los contenidos y codiseñadores de las actividades de aprendizaje de un curso, es decir, un sistema donde cada elemento tiene un papel activo en el aprendizaje e interactúan de tal forma que cada experiencia es inédita.

Igualmente, este tema, que repunta con fuerza en la actual pandemia, se ha discutido desde sus particularidades narrativas que complementan y potencian la hipertextualidad y la multimedialidad (Giraldo-Ramírez, 2008), con narrativas más actuales como las denominadas transmedia (Jenkins, 2010), aplicadas a la elaboración de contenidos educativos digitales (Saavedra-Bautista et al., 2017).

\section{Metodología: un contexto para una lectura específica de la apropiación de TIC en educación}

Tal como se afirmó, es conveniente que un estudio acerca de la apropiación de TIC en docentes se aborde desde los distintos escenarios y desde las prácticas que conforman la actividad pedagógica. En este caso, se recogieron datos cualitativos mediante el levantamiento de experiencias de docentes (Jara, 2001) y datos cuantitativos con un instrumento propio que permitió identificar las tendencias en el uso de TIC y en la elaboración y uso de contenidos educativos digitales de esta comunidad universitaria. Los resultados que aquí se describen y discuten corresponden a la fase cuantitativa del estudio.

El instrumento tipo encuesta está formado por un total de 70 ítems distribuidos en seis secciones, usando escala tipo Likert de cinco niveles para la sección uno, dos y tres; y escala de frecuencias de cinco niveles para las tres restantes: la sección uno (1) se denominó uso de TIC en el proceso de docencia, la dos (2) aspectos para tener en cuenta a la hora de elegir un recurso TIC, la tres (3) posibilidades y limitaciones relativas al uso de las TIC, la cuatro (4) herramientas TIC para su práctica docente, la cinco (5) estrategias metodológicas que usa con TIC y, la sección seis, (6) formación en el uso y elaboración de contenidos educativos digitales. Sobre el instrumento, se 
hizo una evaluación de confiabilidad mediante Alpha de Cronbach (ver Tabla 1), resultados que mostraron una consistencia interna alta, debido a que, en todas las secciones del instrumento, el resultado del Alpha fue superior a 0,7.

\section{Tabla 1}

Medición de confiabilidad del instrumento aplicado a los docentes (Alpha de Cronbach por secciones)

\begin{tabular}{|l|c|}
\hline Secciones & Alpha \\
\hline Uso de TIC en el proceso de docencia & 0,8343 \\
\hline Aspectos a tener en cuenta a la hora de elegir un recurso TIC & 0,8651 \\
\hline Posibilidades y limitaciones relativas al uso de las TIC & 0,7388 \\
\hline Herramientas TIC para su práctica docente & 0,9194 \\
\hline Estrategias metodológicas que usa con TIC & 0,8541 \\
\hline Formación en el uso y elaboración de contenidos educativos digitales & 0,8073 \\
\hline
\end{tabular}

Fuente: elaboración propia.

La encuesta se aplicó a docentes de la Universidad Pontificia Bolivariana (UPB), de las cuatro sedes que tiene la institución ${ }^{\mathrm{iii}}$ y que imparten cursos en el nivel de formación superior en todas las áreas de conocimiento agrupadas en ocho escuelas. ${ }^{\text {iv }}$ El universo disponible fue de 1388 docentes, a quienes se les envió la encuesta y respondieron voluntariamente 404 docentes (ver Tabla 2). Se destaca que la gran mayoría de personas encuestadas corresponde a docentes de la sede Medellín (58\%), seguidos de la sede Bucaramanga (25\%), Montería (11\%) y Palmira (6\%). Adicionalmente, se destaca que el $58 \%$ de la muestra (235) son hombres y el restante $42 \%$ son mujeres (169).

\section{Tabla 2}

Población, muestra y aplicación de instrumento en las sedes de la institución

\begin{tabular}{|l|l|l|}
\hline Sedes & Universo & Muestra \\
\hline Medellín & 964 & 236 \\
\hline Bucaramanga & 207 & 101 \\
\hline Montería & 141 & 45 \\
\hline Palmira & 76 & 22 \\
\hline Totales & 1388 & 404 \\
\hline
\end{tabular}

Fuente: elaboración propia.

\section{Características de la población}

Se entrevistaron docentes de todas las escuelas de la institución objeto de estudio. La Escuela de Ingenierías tiene la mayor presencia dentro de la muestra con el 34,9\%, seguido por la 
Escuela de Ciencias Sociales con el 19,6\%. La escuela con menor representación dentro de la muestra corresponde a la de Educación y Pedagogía con el 5\%.

\section{Gráfico 1}

Escuela a la que pertenecen los docentes encuestados

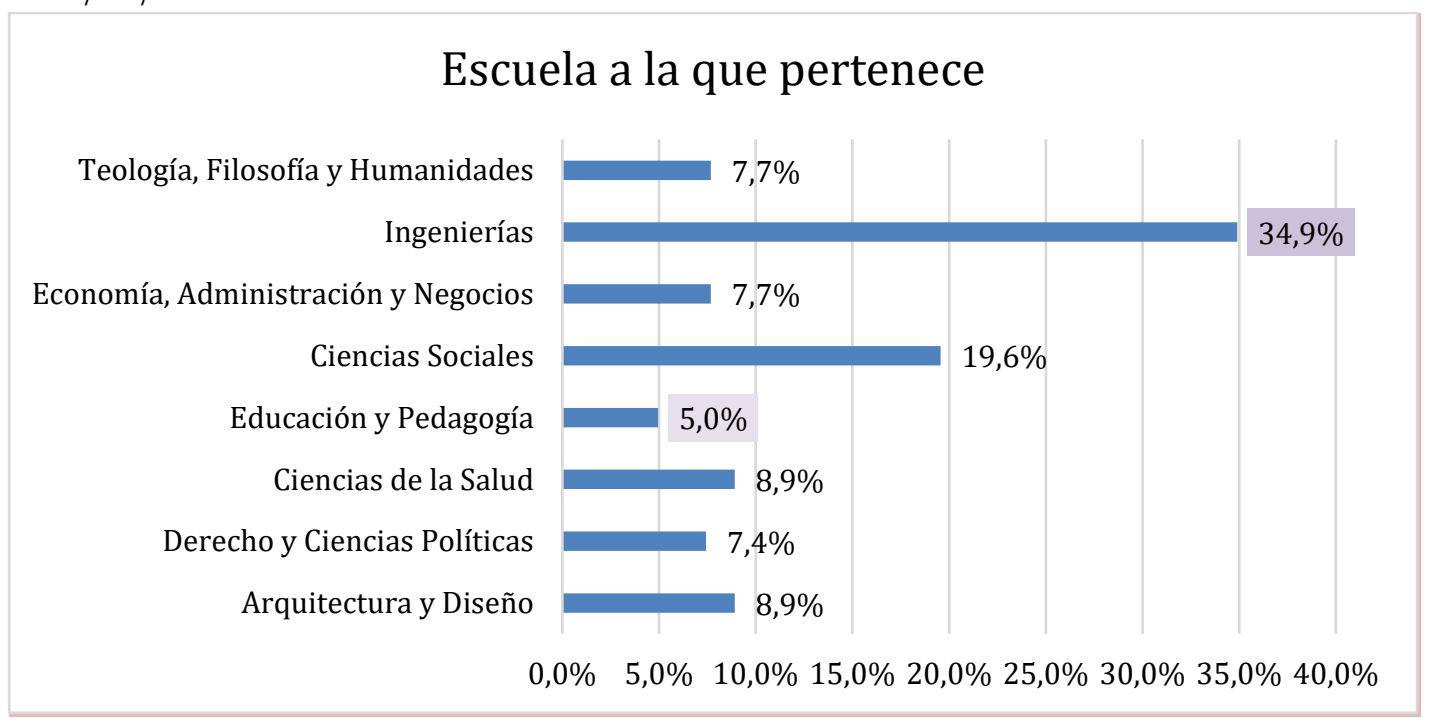

Fuente: elaboración propia.

En cuanto al último nivel de formación alcanzado, la muestra de docentes encuestados/as denota un alto porcentaje de docentes con formación de maestría 58,4\%, con formación doctoral el $24,8 \%$, a nivel de especialización el 11,9\% y a nivel de pregrado el 5\%. Ver Gráfico 2.

\section{Gráfico 2}

Último nivel de formación alcanzado por los docentes

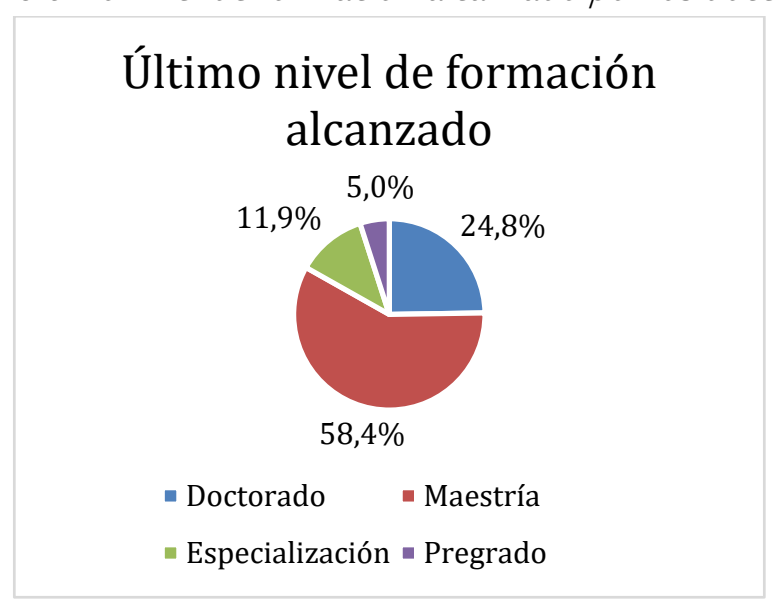

Fuente: elaboración propia. 
En relación con la categoría en el escalafón docente, se evidencia una relativa paridad entre la cantidad de docentes titulares, que es el nivel más alto del escalafón (36,1\%), con docentes asociados, que es el segundo nivel del escalafón (37,4\%). El 22\% de los y las docentes en la muestra son asistentes y el $4 \%$ auxiliares.

\section{Gráfico 3}

Categoría alcanzada en el escalafón docente

\section{Categoría en el escalafón docente.}

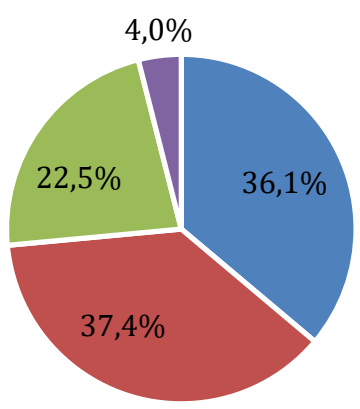

- Titular $\backsim$ Asociado $\backsim$ Asistente - Auxiliar

Es importante resaltar las actividades académicas realizadas por las personas encuestadas, donde las dos actividades de mayor concentración son docencia, con un 45,8\%, y docencia e investigación, con un 44,1\%. En el Gráfico 4 se pueden observar las tendencias de las actividades realizadas por docentes.

\section{Gráfico 4}

Actividades académicas realizadas por los docentes

\section{Sus actividades académicas se concentran principalmente en:}

\begin{tabular}{|c|c|c|c|c|}
\hline $50,0 \%$ & $45,8 \%$ & & & $44,1 \%$ \\
\hline $40,0 \%$ & & & & \\
\hline $30,0 \%$ & & & & \\
\hline $20,0 \%$ & & $9,4 \%$ & & \\
\hline $10,0 \%$ & & & $0,7 \%$ & \\
\hline & Docencia & Investigación & Transferencia & $\begin{array}{l}\text { Docencia } \\
\text { investigaci }\end{array}$ \\
\hline
\end{tabular}




\section{Resultados}

Tendencias generales en el uso de TIC y contenidos digitales

En general, el uso que cada docente hace de las TIC en sus prácticas se enfoca a la orientación al estudiante, tanto en la promoción de su uso como de su acceso, pues, en las dos primeras secciones, estos aspectos obtuvieron las valoraciones más altas por parte de los docentes. Estas respuestas confirman la creencia, generalizada, de que el uso de TIC motiva a los y las estudiantes. De manera complementaria, cuando se les indagó por las posibilidades y limitaciones relativas al uso de TIC, las/os docentes le dieron un puntaje muy bajo al hecho de que las TIC pudieran ser distractores en la clase, lo que muestra una visión positiva de su uso por parte de estudiantes. Ver Tabla 3.

\section{Tabla 3}

Uso de TIC en el proceso de docencia y aspectos relevantes a la hora de elegir un recurso TIC

\begin{tabular}{|c|c|c|c|}
\hline \multicolumn{2}{|l|}{ Uso de TIC en el proceso de docencia } & \multicolumn{2}{|c|}{$\begin{array}{l}\text { Aspectos relevantes a la hora de elegir un recurso } \\
\text { TIC }\end{array}$} \\
\hline Ítem & $\begin{array}{l}\text { Puntaje } \\
\text { promedio }\end{array}$ & Ítem & $\begin{array}{l}\text { Puntaje } \\
\text { promedio }\end{array}$ \\
\hline $\begin{array}{l}\text { Promover el uso de herramientas } \\
\text { TIC en los estudiantes como parte } \\
\text { de su actividad docente es }\end{array}$ & 4,53 & Accesibilidad para los estudiantes & 4,68 \\
\hline $\begin{array}{l}\text { El aprendizaje del manejo de } \\
\text { herramientas o aplicaciones TIC de } \\
\text { forma autónoma es }\end{array}$ & 4,51 & Facilidad de uso & 4,59 \\
\hline $\begin{array}{l}\text { La política educativa de la } \\
\text { institución referida al uso de las TIC } \\
\text { en la práctica docente es para } \\
\text { usted es }\end{array}$ & 4,46 & $\begin{array}{l}\text { Motivación que genera en los } \\
\text { estudiantes }\end{array}$ & 4,58 \\
\hline \multirow[t]{5}{*}{$\begin{array}{l}\text { La elaboración de contenidos } \\
\text { digitales educativos propios o de } \\
\text { su autoría es para usted }\end{array}$} & 4,30 & Tiempo de dedicación que le exige & 4,53 \\
\hline & & Relevancia científica y profesional & 4,50 \\
\hline & & Innovación tecnológica y didáctica & 4,48 \\
\hline & & $\begin{array}{l}\text { Problema de aprendizaje que } \\
\text { resuelve }\end{array}$ & 4,48 \\
\hline & & $\begin{array}{l}\text { Conocimiento que posee sobre el } \\
\text { recurso o herramienta }\end{array}$ & 4,40 \\
\hline
\end{tabular}

Fuente: elaboración propia.

Otro asunto por destacar está en el uso predecible y poco especializado de recursos TIC para la docencia. Los resultados confirman que lo más usado son las herramientas de siempre en las que somos usuarios hace más de 20 años, es decir, todo el paquete Office, y las herramientas básicas de comunicación como el correo electrónico. Con lo cual, la exploración de herramientas es poca y también es poco el uso de herramientas especializadas para actividades de 
procesamiento de datos multimedia, en especial para audio y video. También se ve un uso muy bajo de redes sociales para asuntos educativos y todavía menos el uso de herramientas que permitirían crear contenidos digitales, por ejemplo: editores de portales, herramientas para gestionar objetos virtuales y las de microblogging para crear contenidos o ser líderes de temas en redes sociales (ver Tabla 4).

\section{Tabla 4}

Herramientas TIC usadas en la práctica docente

\begin{tabular}{|c|c|}
\hline Item & $\begin{array}{l}\text { Puntaje } \\
\text { promedio }\end{array}$ \\
\hline Procesadores de texto (Word, Word Office, etc.) & 4,56 \\
\hline Herramientas de búsqueda (Buscadores Google, Yahoo, metabuscadores) & 4,43 \\
\hline Creador de presentaciones visuales (Power Point, Prezzi, Powtoon, Sway) & 4,37 \\
\hline Bibliotecas digitales y bases de datos de consulta & 3,98 \\
\hline Herramientas de almacenamiento en la nube (Google Drive, Onedrive, DropBox, box) & 3,78 \\
\hline Hojas de cálculo (Excel, otras) & 3,66 \\
\hline Almacenamiento y consulta de videos (Youtube, Vimeo) & 3,63 \\
\hline Herramientas web 2.0 (Google docs, Offices 365) & 3,59 \\
\hline Programas de mensajería integrada (WhatsApp, Telegram, entre otros) & 3,28 \\
\hline Gestores de referencias bibliográficas (Zotero, Mendeley) & 2,89 \\
\hline Plataformas de aprendizaje E-learning (Moodle, Brightspace, Canvas, entre otras) & 2,89 \\
\hline Herramientas para desarrollar mapas mentales, mapas conceptuales (CmapTools, MindMeister) & 2,83 \\
\hline Herramientas para manejo de derechos de autor y plagio (Turnitin, Plagiarism cheker) & 2,81 \\
\hline Videoconferencias y streaming (Webex, Polycom, Blue Jean, Duo, Skype, entre otros) & 2,67 \\
\hline Wikis, foros, blogs & 2,58 \\
\hline Redes sociales (LinkedIn, Facebook, entre otras) & 2,32 \\
\hline Almacenamiento de fotos y redes sociales de fotos (Picassa, Flickr, Instagram) & 2,20 \\
\hline Herramientas de edición de video (Movie Maker, Wax, Video Microsoft, etc.) & 2,11 \\
\hline Herramientas de edición gráfica (PhotoShop, Picnik) & 2,06 \\
\hline Marcadores sociales (Google bookmarks, del.icio.us, excite bookmark) & 1,94 \\
\hline Herramientas de intercambio de archivos (Emule, Torrensts,) & 1,88 \\
\hline Herramientas para gestionar objetos virtuales de aprendizaje (Exelearning, Office MIX, entre otros) & 1,79 \\
\hline Editores de portales, sitios o página web (Microsoft visual studio express for web, sublime text) & 1,79 \\
\hline Herramientas de edición de sonido (Audacity) & 1,76 \\
\hline Lectores RSS (feedly, feespot, inoreader, Feedburner, Google Reader entre otros) & 1,75 \\
\hline Microbloging (Twitter) & 1,73 \\
\hline
\end{tabular}

Fuente: elaboración propia.

Con respecto a las estrategias metodológicas con uso de TIC, se pudo observar que las y los docentes siguen teniendo como preferidas en su repertorio el aprendizaje basado en 
problemas, en casos y en proyectos, aunque las calificaciones no superan el cuatro en ninguna de las estrategias preguntadas. Llama la atención el hecho de que los ítems con menos puntaje son la participación en proyectos de innovación educativa, la implementación de cursos virtuales y el uso de webquest, dado que son temas de actualidad señalados en las distintas tendencias educativas. Se evidencia, además, la necesidad de capacitación y apoyo a los docentes en el tema de estrategias metodológicas, con el fin de que estas puedan incorporarse a sus procesos de enseñanza (ver Tabla 5).

\section{Tabla 5}

Estrategias metodológicas apoyadas con TIC

\begin{tabular}{|l|l|}
\hline Item & \multicolumn{1}{|c|}{ Puntaje } \\
\hline Apromedio \\
\hline Estudios de caso & 3,79 \\
\hline Aprendizaje Basado en Proyectos & 3,59 \\
\hline Implementación de Trabajo Colaborativo & 3,51 \\
\hline Participa en actividades formativas relacionadas con el uso de las TIC para su docencia. & 3,48 \\
\hline Utiliza herramientas de Software Libre & 3,29 \\
\hline Utiliza los servicios de apoyo para la implementación de las TIC que se proporcionan desde su & 3,00 \\
\hline universidad & 2,95 \\
\hline Imparte formación relacionada con el uso de TIC a sus estudiantes & 2,91 \\
\hline Aprendizaje basado en evidencias & 2,78 \\
\hline Atiende a sus estudiantes en tutoría virtual & 2,76 \\
\hline Aprendizaje basado en retos & 2,56 \\
\hline Participa en foros o espacios de reflexión donde se intercambian experiencias pedagógicas con TIC & 2,46 \\
\hline Aula Invertida & 2,35 \\
\hline Participa en proyectos de innovación educativa con TIC (Últimos 5 años) & 2,31 \\
\hline Implementa cursos en modalidad virtual (E-Learningo Blended Learning) & 2,30 \\
\hline Uso de Webquest & 1,48 \\
\hline
\end{tabular}

Fuente: elaboración propia.

En la sección correspondiente a formación en el uso y elaboración de contenidos digitales, se pudieron ver puntajes más altos en la formación general en contenidos digitales y recursos educativos para los cursos de docentes, y menores en temas relacionados con los usos y formación especializada, por ejemplo, desde los objetos virtuales. También se evidencian puntajes altos referidos al poco conocimiento que se tiene de los recursos propios de la institución y una preferencia por buscar materiales diferentes a los creados en la universidad. Las respuestas mostraron que, mientras más específicos los recursos y la formación en contenidos, menos atractiva para los docentes. Con ello, puede inferirse que, para el docente, este tema aún es un asunto muy general (ver Tabla 6). 


\section{Tabla 6}

Formación en el uso y elaboración de contenidos educativos digitales

\begin{tabular}{|l|l|}
\hline Ítem & Puntaje promedio \\
\hline Contenidos digitales para sus cursos & 3,33 \\
\hline Recursos educativos digitales abiertos para sus cursos & 2,95 \\
\hline $\begin{array}{l}\text { Material didáctico propio publicación a través de internet o en plataformas } \\
\text { educativas (abiertas o privadas) }\end{array}$ & 2,92 \\
$\begin{array}{l}\text { Plataformas y repositorios de recursos digitales de la UPB } \\
\begin{array}{l}\text { Contenidos digitales producidos por la UPB (Centro de Producción } \\
\text { Audiovisual, UPB Virtual, Emisora, etc.) }\end{array}\end{array}$ & 2,63 \\
\hline Cursos con objetos virtuales de aprendizaje (OVA) & 2,21 \\
\hline
\end{tabular}

Fuente: elaboración propia.

\section{Algunas especificidades importantes en el análisis de las prácticas docentes El nivel formativo y el uso de TIC}

Las/os docentes con maestría puntearon con mayor importancia el manejo de herramientas TIC de forma autónoma, mientras que quienes contaban con nivel de especialización y pregrado le dieron mayor importancia a la promoción del uso de herramientas TIC en el estudiantado como parte de la actividad docente. Las/os docentes con doctorado fueron quienes puntearon con las calificaciones más bajas. En general, se puede ver que quienes poseen menor nivel formativo encuentran mayores beneficios y menos obstáculos y limitaciones en las TIC. Por el contrario, quienes alcanzaron el nivel de doctorado les otorgan menos puntaje a los ítems (ver Tabla 7).

\section{Tabla 7}

Uso de TIC en el proceso de docencia y el nivel formativo de docentes

\begin{tabular}{|c|c|c|c|c|}
\hline & Doctorado & Maestría & Especialización & Pregrado \\
\hline $\begin{array}{r}\text { La política educativa de la institución } \\
\text { referida al uso de las TIC en la práctica } \\
\text { docente }\end{array}$ & 4,28 & 4,51 & 4,52 & 4,65 \\
\hline $\begin{array}{r}\text { El aprendizaje del manejo de } \\
\text { herramientas o aplicaciones TIC de forma } \\
\text { autónoma }\end{array}$ & 4,39 & 4,57 & 4,54 & 4,40 \\
\hline $\begin{array}{r}\text { Promover el uso de herramientas TIC en } \\
\text { los estudiantes como parte de su } \\
\text { actividad docente }\end{array}$ & 4,34 & 4,56 & 4,73 & 4,65 \\
\hline $\begin{array}{l}\text { La elaboración de contenidos digitales } \\
\text { educativos propios o de su autoría }\end{array}$ & 4,09 & 4,35 & 4,46 & 4,40 \\
\hline
\end{tabular}

Fuente: elaboración propia. 
En relación con las herramientas para la práctica docente, se observaron pocas diferencias entre los niveles de formación. De este modo, tanto docentes con doctorado, maestría, especialización y pregrado obtuvieron las mayores puntuaciones en las mismas tres herramientas TIC: los procesadores de texto, los creadores de presentaciones visuales y las herramientas de búsqueda. Resulta particular observar que, siendo las/os docentes con pregrado las/os más jóvenes, estas/os tengan puntajes más bajos en el uso de casi todas las herramientas; mientras que, quienes cuentan con formación doctoral, evidencian un puntaje levemente más alto. Solo se destacan diferencias amplias entre los niveles de formación de docentes en el uso de los gestores de referencias bibliográficas. Allí, el puntaje más alto se da en quienes tienen maestrías y, el más bajo, en docentes con pregrado ver (Tabla 8).

\section{Tabla 8}

Herramientas TIC para la práctica docente por niveles de formación

\begin{tabular}{|c|c|c|c|c|}
\hline & Doctorado & Maestría & Especialización & Pregrado \\
\hline Procesadores de texto (Word, Word Office, etc.) & 4,66 & 4,54 & 4,44 & 4,50 \\
\hline $\begin{array}{l}\text { Creador de presentaciones visuales (PowerPoint, } \\
\text { Prezzi, Powtoon, Sway) }\end{array}$ & 4,48 & 4,39 & 4,27 & 3,95 \\
\hline Hojas de cálculo (Excel, otras) & 3,74 & 3,74 & 3,42 & 2,85 \\
\hline $\begin{array}{l}\text { Programas de mensajería integrada (WhatsApp, } \\
\text { Telegram, entre otros) }\end{array}$ & 3,07 & 3,35 & 3,56 & 2,95 \\
\hline [35. Microbloging (Twitter) & 1,54 & 1,77 & 1,98 & 1,55 \\
\hline Redes sociales (Linkedln, Facebook, entre otras) & 2,10 & 2,39 & 2,52 & 2,10 \\
\hline Herramientas web 2.0 (Google docs, Offices 365) & 3,66 & 3,63 & 3,25 & 3,55 \\
\hline Wikis, foros, blogs & 2,36 & 2,73 & 2,48 & 2,15 \\
\hline $\begin{array}{l}\text { Herramientas de intercambio de archivos } \\
\text { (Emule, Torrensts) }\end{array}$ & 1,81 & 1,94 & 1,85 & 1,70 \\
\hline $\begin{array}{l}\text { Herramientas de almacenamiento en la nube } \\
\text { (Google Drive, Onedrive, DropBox, box) }\end{array}$ & 3,89 & 3,80 & 3,54 & 3,65 \\
\hline $\begin{array}{l}\text { Herramientas de búsqueda (Buscadores Google, } \\
\text { Yahoo, metabuscadorees) }\end{array}$ & 4,49 & 4,45 & 4,23 & 4,30 \\
\hline $\begin{array}{l}\text { Almacenamiento de fotos y redes sociales de } \\
\text { fotos (Picassa, Flickr, Instagram) }\end{array}$ & 2,08 & 2,23 & 2,29 & 2,15 \\
\hline $\begin{array}{l}\text { Almacenamiento y consulta de videos (Youtube, } \\
\text { Vimeo) }\end{array}$ & 3,54 & 3,67 & 3,63 & 3,50 \\
\hline $\begin{array}{l}\text { Marcadores sociales (Google bookmarks, } \\
\text { del.icio.us, excite bookmark) }\end{array}$ & 1,95 & 2,00 & 1,65 & 1,85 \\
\hline $\begin{array}{l}\text { Lectores RSS (feedly, feespot, inoreader, } \\
\text { Feedburner, google reader entre otros) }\end{array}$ & 1,68 & 1,86 & 1,58 & 1,25 \\
\hline $\begin{array}{l}\text { Editores de portales, sitios o página web } \\
\text { (Microsft visual studio express for web, sublime } \\
\text { text) }\end{array}$ & 1,61 & 1,91 & 1,58 & 1,75 \\
\hline $\begin{array}{l}\text { Herramientas para gestionar objetos virtuales de } \\
\text { aprendizaje (Exelearning, Office MIX, entre otros) }\end{array}$ & 1,66 & 1,84 & 1,73 & 2,05 \\
\hline
\end{tabular}




\begin{tabular}{|c|c|c|c|c|}
\hline & Doctorado & Maestría & Especialización & Pregrado \\
\hline $\begin{array}{l}\text { Herramientas de edición gráfica (PhotoShop, } \\
\text { Picnik) }\end{array}$ & 1,97 & 2,11 & 1,96 & 2,15 \\
\hline Herramientas de edición de sonido (Audacity) & 1,61 & 1,83 & 1,60 & 2,05 \\
\hline $\begin{array}{l}\text { Herramientas de edición de video (Movie Maker, } \\
\text { Wax, Video Microsoft, etc.) }\end{array}$ & 2,04 & 2,18 & 1,90 & 2,20 \\
\hline $\begin{array}{l}\text { Herramientas para desarrollar mapas mentales, } \\
\text { mapas conceptuales (CmapTools, MindMeister) }\end{array}$ & 2,76 & 2,89 & 2,63 & 2,85 \\
\hline $\begin{array}{l}\text { Plataformas de aprendizaje E-learning (Moodle, } \\
\text { Brightspace, Canvas, entre otras) }\end{array}$ & 2,66 & 3,03 & 2,85 & 2,55 \\
\hline $\begin{array}{l}\text { Videoconferencias y streaming (Webex, } \\
\text { Polycom, Blue Jean, Duo, Skype, entre otros) }\end{array}$ & 2,84 & 2,71 & 2,44 & 2,00 \\
\hline Bibliotecas digitales y bases de datos de consulta & 4,28 & 3,98 & 3,48 & 3,70 \\
\hline $\begin{array}{l}\text { Herramientas para manejo de derechos de autor } \\
\text { y plagio (Turnitin, Plagiarism cheker) }\end{array}$ & 3,04 & 2,83 & 2,35 & 2,50 \\
\hline $\begin{array}{l}\text { Gestores de referencias bibliográficas (Zotero, } \\
\text { Mendeley) }\end{array}$ & 3,33 & 2,90 & 2,27 & 2,10 \\
\hline
\end{tabular}

Fuente: elaboración propia.

En cuanto a la formación en el uso y elaboración de contenidos digitales, hay una diferencia, no muy significativa, entre docentes con formación doctoral y docentes con pregrado, en donde el primer grupo tiene un porcentaje mayor en el uso de material didáctico propio. Se destaca que el nivel de formación doctoral tiene los puntajes más altos en recursos educativos digitales abiertos para cursos, material didáctico propio, contenidos digitales producidos por la universidad y plataformas y repositorios de UPB, denotando una intención de uso de recursos, plataformas y contenidos trabajados en la universidad (ver Tabla 9).

\section{Tabla 9}

Uso y elaboración de contenidos educativos digitales por formación docente

\begin{tabular}{|c|c|c|c|c|}
\hline & Doctorado & Maestría & Especialización & Pregrado \\
\hline Cursos con objetos virtuales de aprendizaje & 1,77 & 2,08 & 1,90 & 2,15 \\
\hline Contenidos digitales para sus cursos & 3,36 & 3,36 & 2,98 & 3,70 \\
\hline $\begin{array}{l}\text { Recursos educativos digitales abiertos para sus } \\
\text { cursos }\end{array}$ & 3,13 & 2,98 & 2,42 & 3,00 \\
\hline $\begin{array}{l}\text { Material didáctico propio publicación a través de } \\
\text { internet o en plataformas educativas (abiertas o } \\
\text { privadas) }\end{array}$ & 3,31 & 2,82 & 2,69 & 2,70 \\
\hline $\begin{array}{l}\text { Contenidos digitales producidos por la UPB } \\
\text { (Centro de Producción Audiovisual, UPB Virtual, } \\
\text { Emisora, etc.) }\end{array}$ & 2,28 & 2,21 & 2,08 & 2,15 \\
\hline
\end{tabular}


Plataformas y repositorios de recursos digitales

de la UPB

Fuente: elaboración propia.

\section{Las áreas de conocimiento de docentes y el uso de TIC}

En general, todas las escuelas otorgan puntajes altos a la importancia del uso de TIC en el proceso de docencia. Sin embargo, las escuelas que valoran con puntajes más altos los ítems de esta sección son Ciencias de la Salud, Educación y Derecho. Cuando se trata de elegir un recurso TIC, los puntajes entre las escuelas tampoco tienen muchas diferencias y son bastante altos, es decir, todos los aspectos consultados sobre lo que es más importante a la hora de elegir un recurso TIC tiene una alta valoración.

\section{Tabla 10}

\section{Uso de TIC en el proceso de docencia por Escuelas}

\begin{tabular}{|c|c|c|c|c|c|c|c|c|}
\hline & 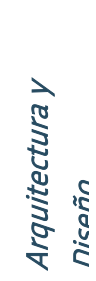 & 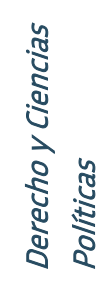 & 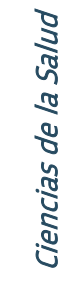 & 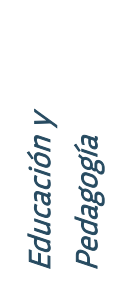 & 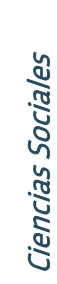 & 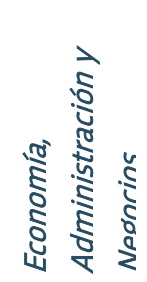 & 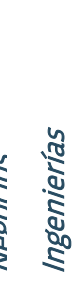 & 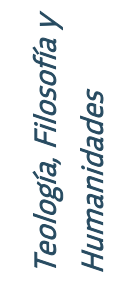 \\
\hline $\begin{array}{l}\text { La política educativa de la institución referida al uso } \\
\text { de las TIC en la práctica docente }\end{array}$ & 4,08 & 4,57 & 4,67 & 4,65 & $\begin{array}{l}4, \\
47\end{array}$ & 4,32 & $\begin{array}{l}4, \\
48\end{array}$ & 4,48 \\
\hline $\begin{array}{l}\text { El aprendizaje del manejo de herramientas o } \\
\text { aplicaciones TIC de forma autónoma }\end{array}$ & 4,19 & 4,67 & 4,61 & 4,55 & $\begin{array}{l}4, \\
46\end{array}$ & 4,52 & $\begin{array}{l}4, \\
57\end{array}$ & 4,48 \\
\hline $\begin{array}{l}\text { Promover el uso de herramientas TIC en los } \\
\text { estudiantes como parte de su actividad docente }\end{array}$ & 4,31 & 4,67 & 4,64 & 4,65 & $\begin{array}{l}4, \\
53\end{array}$ & 4,48 & $\begin{array}{l}4, \\
58\end{array}$ & 4,29 \\
\hline $\begin{array}{l}\text { La elaboración de contenidos digitales educativos } \\
\text { propios o de su autoría }\end{array}$ & 4,06 & 4,27 & 4,28 & 4,45 & $\begin{array}{l}4, \\
25\end{array}$ & 4,06 & $\begin{array}{l}4, \\
43\end{array}$ & 4,32 \\
\hline
\end{tabular}

Fuente: elaboración propia.

Sobre la valoración de posibilidades y limitaciones, se puede decir que los puntajes son muy variables y que no están en rangos elevados. Por ejemplo, llama la atención que, frente a las TIC y su ampliación de la comunicación interpersonal, todos los puntajes estén por debajo de cuatro, con lo cual hay una percepción generalizada de que, si bien el uso de herramientas tecnológicas ofrece una posibilidad comunicativa importante para las relaciones interpersonales, esta no es un argumento contundente o con el que los entrevistados estén totalmente de acuerdo (ver Tabla 11).

En general, como ya se ha planteado, se detecta una visión positiva de las/os docentes acerca de las posibilidades que ofrecen las TIC. Y si bien este resultado pareciera ser predecible, 
puede ser contundente a la hora de examinar los estudios que más de una década atrás consultaba a docentes sobre sus usos y percepciones. Un estudio realizado por el grupo de Investigación en Educación en Ambientes Virtuales (EAV) de la UPB, en el 2005 (López-Vélez), evidenció que aún había mucha resistencia por parte del personal docente al uso de herramientas TIC en sus prácticas. Hoy, los docentes tienen clara su función, pero hacen usos muy básicos de las TIC, tanto en su práctica docente como investigativa (Álvarez-Cadavid et al., 2017).

\section{Tabla 11}

Posibilidades y limitaciones relativas al uso de las TIC por escuelas

\begin{tabular}{|c|c|c|c|c|c|c|c|c|}
\hline & 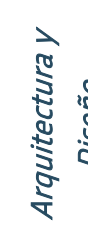 & 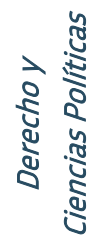 & 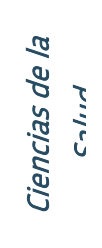 & 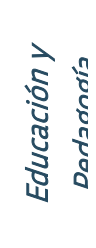 & 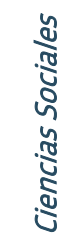 & 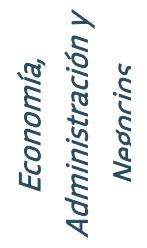 & 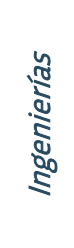 & 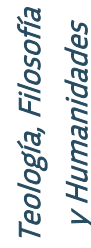 \\
\hline $\begin{array}{r}\text { Considero que el uso de TIC en mi práctica } \\
\text { docente es muy importante }\end{array}$ & 4,03 & 4,33 & 4,33 & 4,45 & 4,39 & 4,35 & 4,38 & 4,19 \\
\hline $\begin{array}{r}\text { Las TIC posibilitan el manejo flexible de los } \\
\text { espacios (presenciales y virtuales) para la } \\
\text { realización de encuentros. }\end{array}$ & 4,22 & 4,47 & 4,50 & 4,45 & 4,43 & 4,23 & 4,33 & 3,97 \\
\hline Las TIC amplían la comunicación interpersonal & 3,89 & 3,97 & 3,89 & 3,90 & 3,78 & 3,68 & 3,79 & 3,32 \\
\hline $\begin{array}{l}\text { Las TIC permiten el acceso permanente a la } \\
\text { información }\end{array}$ & 4,56 & 4,63 & 4,31 & 4,60 & 4,52 & 4,48 & 4,48 & 4,10 \\
\hline $\begin{array}{r}\text { Las TIC posibilitan el manejo flexible de los } \\
\text { horarios }\end{array}$ & 4,25 & 4,40 & 4,42 & 4,60 & 4,39 & 4,61 & 4,30 & 4,03 \\
\hline $\begin{array}{l}\text { Las TIC permiten diversidad metodológica en } \\
\qquad \text { la enseñanza y el aprendizaje }\end{array}$ & 4,17 & 4,63 & 4,47 & 4,45 & 4,39 & 4,23 & 4,25 & 4,06 \\
\hline $\begin{array}{r}\text { Las TIC posibilitan mejoras de los procesos de } \\
\text { evaluación }\end{array}$ & 3,81 & 4,23 & 4,19 & 4,00 & 4,10 & 4,13 & 4,06 & 3,52 \\
\hline $\begin{array}{l}\text { Las TIC implican la dependencia de equipos } \\
\text { técnicos y dispositivos para su acceso }\end{array}$ & 4,31 & 4,07 & 4,44 & 4,50 & 4,35 & 4,19 & 4,13 & 4,45 \\
\hline $\begin{array}{r}\text { El uso de TIC traen consigo fallos técnicos que } \\
\text { impiden los procesos educativos }\end{array}$ & 3,61 & 3,40 & 3,36 & 3,65 & 3,32 & 3,35 & 3,06 & 3,48 \\
\hline $\begin{array}{l}\text { Las TIC son un elemento distractor para los } \\
\text { estudiantes y ello dificulta el trabajo docente. }\end{array}$ & 2,64 & 2,70 & 2,47 & 2,50 & 2,51 & 2,68 & 2,46 & 2,45 \\
\hline
\end{tabular}

Fuente: elaboración propia.

\section{- Aspectos generacionales en el uso de TIC por parte de los docentes}

En general, los porcentajes de uso de todas las herramientas mencionadas en el instrumento presentan puntajes mayores cuando las/os docentes son más jóvenes. No obstante, vale la pena señalar algunas diferencias que se observaron al analizar los resultados. 
En el ítem del uso de TIC en los procesos de evaluación, la visión más favorable la tiene el personal docente de 61 años en adelante, lo cual resulta un poco sorprendente porque no es claro si este grupo hace un uso concreto de estas herramientas en sus prácticas o si el resultado solo obedece a un asunto discursivo más que de práctica.

A mayor edad del equipo docente, más valoran la posibilidad de elaborar sus propios recursos. Este resultado podría tener dos interpretaciones: una asociada a la madurez académica de las profesoras y los profesores, en donde ya pueden contar con material y datos propios, producto de su experiencia docente e investigativa; mientras que el personal más joven está apenas configurando y apropiando el saber. Este resultado podría ser confuso si se asume que las y los docentes jóvenes dominan más las TIC y ello les facilitaría, desde el punto de vista técnico, la elaboración de material propio. De igual manera, se podría asumir que las y los jóvenes, hoy, localizan contenido más especializado y, con ello, se desestimula la elaboración de material propio. Sin embargo, asumimos que, en este ítem, influye más la trayectoria en el dominio del saber y, por tanto, resulta lógico que docentes de más edad sientan que deberían crear su propio material (ver Tabla 12).

\section{Tabla 12}

Uso de TIC en la labor docente por edades

\begin{tabular}{|c|c|c|c|c|c|}
\hline Ítem & $\begin{array}{l}30 \text { o } \\
\text { menos }\end{array}$ & $\begin{array}{l}31 \mathrm{a} \\
40\end{array}$ & $\begin{array}{l}41 a \\
50\end{array}$ & $\begin{array}{l}51 a \\
60\end{array}$ & $\begin{array}{l}61 \text { y } \\
\text { mas }\end{array}$ \\
\hline $\begin{array}{l}\text { La elaboración de contenidos digitales educativos propios o de su } \\
\text { autoría es para usted }\end{array}$ & 4,29 & 4,45 & 4,51 & 4,44 & 4,52 \\
\hline $\begin{array}{l}\text { Promover el uso de herramientas TIC en los estudiantes como parte de } \\
\text { su actividad docente es }\end{array}$ & 4,50 & 4,51 & 4,54 & 4,44 & 4,67 \\
\hline $\begin{array}{l}\text { El aprendizaje del manejo de herramientas o aplicaciones TIC de forma } \\
\text { autónoma es }\end{array}$ & 4,39 & 4,54 & 4,55 & 4,48 & 4,81 \\
\hline $\begin{array}{l}\text { La política educativa de la institución referida al uso de las TIC en la } \\
\text { práctica docente es para usted }\end{array}$ & 4,46 & 4,33 & 4,26 & 4,26 & 4,38 \\
\hline
\end{tabular}

Fuente: elaboración propia.

\section{Discusión}

\section{- La apropiación como un proceso lento y complejo}

Los resultados anteriores dan pie para plantear algunos asuntos que requieren una mirada aguda y una reflexión mayor en el camino comprensivo de la apropiación de las TIC en la educación. Muestran, claramente, una brecha discursiva entre el concepto que tienen las/os docentes sobre las TIC y lo que realmente usan en su práctica. Si bien se observó una perspectiva positiva, las herramientas más usadas son aquellas que forman parte de su rutina hace más de dos décadas. Las y los docentes conciben en un puntaje alto la importancia de las TIC, pero, cuando se va a la práctica, hay un uso de medio a bajo, tanto en herramientas como en estrategias, y muy bajo en asuntos mucho más específicos como el uso de recursos propios y la 
participación en proyectos de innovación educativa. Se puede afirmar, en este contexto institucional, que las TIC se asumen más como un apoyo a la docencia presencial, en donde las y los docentes son consumidoras/es de contenidos y no tanto productoras/es de los mismos. La situación aquí retratada debe, hoy, tener otros números y, con seguridad, la pandemia disminuyó, forzadamente, la brecha entre el discurso y la práctica y ese será motivo de nuestra próxima publicación, pero el estudio presentado evidencia el ritmo en el que se venía transformado la mediación de TIC en la educación superior.

La esfera de los contenidos digitales y el uso de TIC como vía para entender la apropiación es un espacio idóneo. Sin embargo, no puede limitarse a la verificación de los usos como si ello fuese un fin en sí mismo. Comprender los procesos de transformación de una práctica tan importante como lo es la docencia requiere pausa y reflexión, pues allí participan tanto los recursos materiales como simbólicos que median en la manera en que el ser humano realiza sus actividades, en este caso, una práctica docente que hace parte de la cotidianidad (hoy, una cotidianidad alterada) de las maestras y los maestros en la que, se espera, puedan incorporar la tecnología de su entorno y su tiempo.

Es también necesario mirar todos los matices cuando hablamos de lo tradicional y lo innovador pues, si bien aquí nos referimos a lo tradicional en relación con un uso que ya ocupa una trayectoria en las rutinas docentes y que se asume como un lugar que se domina, y al cual el docente se acomoda, ello no implica que esté mal o que se tenga que atender un imperativo de uso instrumental para darle un aire modernizante a la acción docente. Lo que aquí queremos poner en reflexión es si esas prácticas acostumbradas siguen siendo efectivas para las nuevas generaciones, si esas prácticas van acompañadas con una reflexión sobre las transformaciones que la tecnología les ha planteado a los saberes. En este camino, puede haber toda una gama que va desde herramientas tradicionales con usos innovadores hasta herramientas vanguardistas con usos tradicionales. Sin duda, las preguntas, hoy, se están reacomodando, pero aún nos debemos preguntar: ¿cómo se debe enseñar, hoy, el saber del que somos expertos?, ¿cómo se aprende, hoy, ese saber y cómo aprenden los estudiantes de hoy?

\section{La perspectiva del estudiantado como contraparte de la reflexión sobre los procesos de apropiación de TIC}

Si bien esta investigación no consultó directamente al estudiantado, sí lo hizo desde la perspectiva docente y, en este trayecto, se reconoció la importancia de cuestionar aquello que sabemos sobre cómo aprenden, hoy, los jóvenes sus estrategias de estudio (Angel-Uribe et al., 2015), sus hábitos de lectura y sus propias rutinas de relacionamiento con la tecnología.

Desde este lugar, se encontraron perspectivas frente a los contenidos digitales en donde la interacción entre docentes y estudiantes se renueva; es el caso de la ecología del aprendizaje (Gros y López, 2016; Luckin, 2008) que propende por hacer de los contenidos un punto de encuentro para generar discusiones, donde incluso pueden convertirse en una estrategia de 
aprendizaje, en la cual cada estudiante construya los contenidos del curso. Este enfoque plantea la pregunta por cómo estudiantes y docentes interactúan con los objetos técnicos y de conocimiento, ya no desde un rol pasivo, sino desde la pregunta pedagógica fundamental: ¿es el contenido apropiado para soportar el proceso de aprendizaje? Se vuelve necesario resolver cómo se interactuará con los contenidos en una situación o ambiente de aprendizaje, no es suficiente resolver cómo se presentarán o como apoyarán al docente (Franklin y Plum, 2008; Gros et al., 2012; Gros y López, 2016; Hilton, 2016; Luckin, 2008).

Este énfasis en el estudiante también es reiterado en el trabajo de Rege-Colet, (2017) quien, a su vez, retoma elementos de la Teoría U (Schamer, 2006) donde hay un cambio de un modelo centrado en la difusión de contenidos a un modelo centrado en el aprendizaje. En sus palabras, es poner al estudiante a la autogestión de su aprendizaje para pasar de un aprendizaje centrado en la difusión de información a un modelo que asume al estudiantado como centro del aprendizaje. Dicha perspectiva no solo exige que el personal docente conozca muy bien los estilos de aprendizaje, sino que el mismo estudiantado esté en condiciones de identificar esas capacidades que tiene para aprender.

Es indudable que la pandemia ha reconfigurado la idea que tenemos sobre nuestras/os estudiantes, dado que, en la educación superior, las y los docentes enfrentamos como tema central la experticia en el saber, pero no siempre ello va acompañado de la reflexión sobre la enseñanza y el aprendizaje de ese saber y las maneras en que ese saber es representado para su enseñanza (Litwin et al., 2005) y menos en ambientes altamente mediados por una comunicación remota u online.

Los estudiantes, hoy, están cada vez está más familiarizados con la información audiovisual y con el uso de dispositivos móviles, los cuales les permiten el acceso a otras narrativas y a otras fuentes de información. Por ejemplo, Duarte-Hueros et al. (2016) señalan la preocupación por la formación ética del estudiantado en sus prácticas de descarga de contenidos audiovisuales, la validación del "ethos" académico de las fuentes y el papel del docente. De manera complementaria, el estudio realizado por Hilton (2016) sobre el uso de Recursos Educativos Abiertos (REA) destaca que los estudiantes valoran la facilidad de uso, la actualización de estos frente al material impreso y, en general, prefieren usar los REA como material de apoyo e incluso como alternativa a su formación.

Adicionalmente, esta mirada al estudiantado también debe pasar por las prácticas de lectura y escritura de estas y estos jóvenes cuando acceden al material disponible en internet (Artopoulos, 2011; Canclini et al., 2015; Saavedra-Bautista et al., 2017; Sevillano-García y VázquezCano, 2015), pues mientras menos sepamos de los consumos de información digital de la juventud, más grande será la brecha entre lo que enseñamos, cómo lo enseñamos y lo que finalmente aprenden los y las estudiantes. 


\section{La visión institucional para completar el panorama del trayecto de la apropiación de TIC}

Esta investigación, en su recorrido tanto bibliográfico como en las fuentes directas del contexto institucional, pudo constatar que, si bien el número de recursos ha crecido y se ha sistematizado su almacenamiento y acceso bajo estándares internacionales en los repositorios, no es tan claro para las instituciones el uso pedagógico que se hace de los contenidos por parte de docentes y estudiantes.

Tal como ya se mostró en los datos de esta investigación, el personal docente poco consulta los repositorios universitarios que tienen material propio. Tampoco se cuenta con una estrategia institucional permanente para la divulgación de dicho material y menos con un levantamiento de experiencias de uso en el ambiente de aprendizaje que pueda motivar el trabajo pedagógico de otros y otras docentes.

Contradictoriamente, cada vez, los sistemas de almacenamiento y distribución de información incorporan funcionalidades para conocer el número de usuarios y consultarles por su experiencia de uso, lo cual no sucedía de la misma manera con el material impreso. Hoy, sabemos mucho más de lo que pasa con los contenidos que antes; sin embargo, la incorporación de toda esta experiencia a la labor docente toma su tiempo y demanda que se hagan más investigaciones aplicadas en las instituciones educativas dado que hoy se han diseñado estrategias, en este sentido, motivadas por la contingencia que ha producido el COVID-19.

De esta forma, es importante destacar que, si bien los resultados aquí compartidos mostraron que las y los docentes usan las mismas herramientas que hace 20 años, no se trata, como ya se mencionó, de que tengan que usar las tecnologías más avanzadas, sino de crear los escenarios idóneos para hacer usos acordes a lo que necesita el estudiantado y lo que demanda el saber que se enseña en cada época. Es aquí donde es fundamental que las instituciones educativas cuenten con centros de apoyo a la docencia orientados por políticas administrativas para conseguir una formación de calidad (Cabero-Almenara et al., 2008). Hoy, habría, también, que volver a hacer investigaciones desde estos centros para saber cómo reaccionaron ante la pandemia.

\section{Conclusiones}

Si bien hoy persisten comportamientos convencionales y básicos en el uso de TIC y contenidos digitales en docentes, el recorrido por la literatura muestra que los y las jóvenes exigen cada vez mayor participación en la elaboración de los contenidos que circulan en los medios, incluida la academia. Las fronteras entre el entretenimiento y la información se diluyen y las opciones formativas se diversifican. Lo anterior se suma a las cifras que demuestran el crecimiento de los programas blended y virtuales en todas las instituciones educativas. Hoy, se habla de la tercera generación del e-learning (Gros y García-Peñalvo, 2016) que reclama una participación más activa del estudiantado en ese proceso, donde el aprendizaje móvil, el aumento 
de las interacciones, las implementación de nuevas narrativas, las simulaciones y los escenarios de realidad aumentada van tomando su lugar. En este panorama, la pandemia entró también a hablar con voz propia y veremos no un regreso a la normalidad como la conocíamos, sino la construcción de ambientes híbridos y el replanteamiento de las competencias digitales para la docencia (Selwyn, 2020; Stommel et al., 2020).

Sin embargo, como lo afirma Sabelli (2011), es necesario que las instituciones promuevan no solo el uso per se de las TIC, sino nuevas pedagogías y contenidos acordes con los avances sobre lo que el estudiantado debe saber y lo que requieren para desempeñarse en su vida profesional pospandemia (Reimers y Schleicher, 2020).

Aunque aún se pueda afirmar que son pocos los usuarios que abandonan el rol pasivo (Igarza, 2011), este panorama muestra con claridad una tendencia a otorgarle un papel cada vez más activo cada estudiante, al tiempo que le exige mayor autonomía frente a su proceso de aprendizaje. Esta reiteración, también presente en la literatura, se convierte en un indicador de que esa es la vía para la transformación y el mejoramiento de la calidad de los aprendizajes en las instituciones que, hoy, buscan cómo responder mejor a una sociedad en permanente cambio y que no alcanza a sincronizar su comprensión con las prácticas que ha tenido que implementar sobre la marcha al ritmo de la pandemia.

Las competencias y las habilidades que exigen los tiempos veloces tienden a aumentar la caducidad de las generaciones precedentes, y las exigencias de adaptación, formación permanente y flexibilización que tienden a establecerse como norma constituyen la base de su exclusión futura. (Urresti, 2011, p. 34)

No se imaginaba Urresti, en 2011, la aceleración que viviríamos a principios del 2020, pero sí resulta fundamental pensar en esas exigencias de adaptación permanente que no esperábamos en este ritmo dentro del sector educativo, el cual ha tenido unos ritmos más lentos de transformación. Sin embargo, todo cambio requiere reflexión y pausa para entender lo que pasa y tomar decisiones frente a las exigencias que se nos presenta. Este estudio demostró la lentitud del cambio y solo un seguimiento de investigaciones en distintos momentos nos permitirán entender si las soluciones tecnológicas han transformado o producido nuevas prácticas (Artopoulos, 2011). 


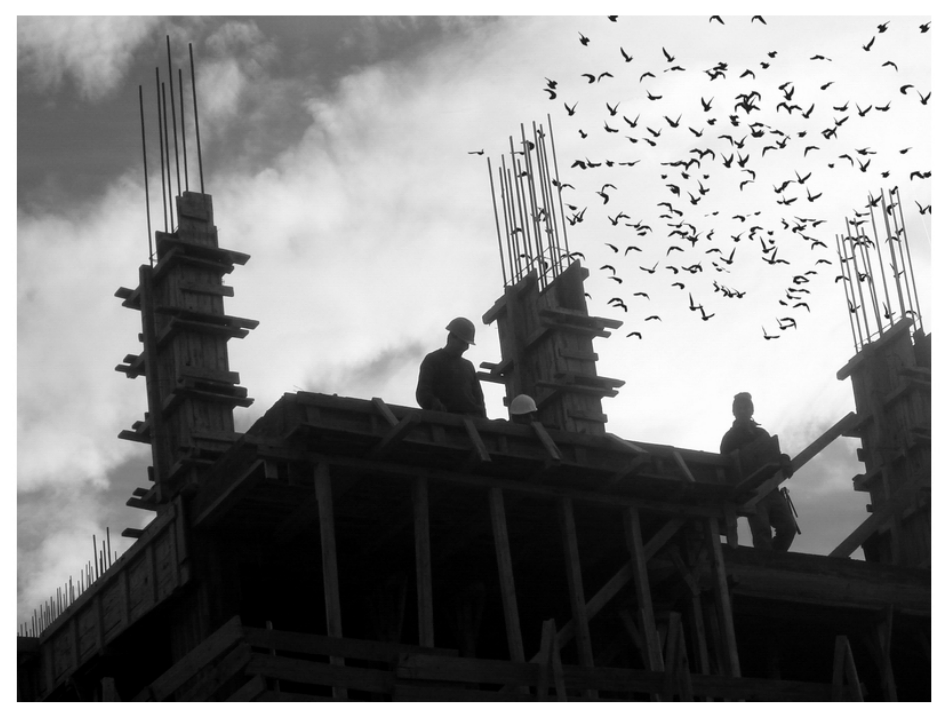

Cuatro paredes sólidas II, fotografía. Alejandro Urioste

\section{Notas}

' Ver: https://www.merlot.org/merlot/index.htm

i Ver: https://repository.upb.edu.co/

iii La Universidad Pontificia Bolivariana tiene cuatro sedes en todo el país: Medellín, Bucaramanga, Palmira y Montería.

iv Las escuelas son: Escuela de Ciencias de la Salud, Escuela de Ciencias Sociales, Escuela de Economía, Administración y Negocios, Escuela de Arquitectura y Diseño, Escuela de Ingenierías, Escuela de Educación y Pedagogía, Escuela de Teología, Filosofía y Humanidades, Escuela de Derecho y Ciencias Políticas.

\section{Bibliografía}

Álvarez-Cadavid, G. M., Giraldo Ramírez, M. E. y Navarro Plazas, C. D. P. (2017). Uso de TIC en investigación cualitativa: discusión y tendencias en la literatura. Katharsis, (23), 239-258. https://doi.org/10.25057/25005731.873

Angel-Uribe I., Vallejo, G. M. y Zambrano, A. J. (2015). Las TIC en las prácticas de estudio: en la búsqueda de estrategias. Revista Q, 9(18), 1-20. https://tinyurl.com/ycjbohxy

Artopoulos, A. (2011). Introducción. En A. Artopoulos (Ed.), La sociedad de las cuatro pantallas. Una mirada Latinoamericana (pp. XV-XXVI). Ariel. https://tinyurl.com/yadgblkp

Cabero-Almenara, J., Lozano, Morales, J. A., Barroso-Osuna, J. M., Fernández-Batanero, J. M., Romero-Tena, R., RománGraván, P. y Llorente-Cejudo, M. C. (2008). Creación de una guía de evaluación/autoevaluación de centros de recursos univesitarios de producción de TICs en la enseñanza. Pixel-Bit. Revista de Medios y Educación, (32), 35-53.

https://idus.us.es/handle/11441/45662

Canclini, N. G., Gerber-Bicecci, V., López-Ojeda, A., Nivón Bolán, E., Pérez Camacho, C., Pinochet Cobos, C. y WinocurIparraguirre, R. (2015). Hacia una antropología de los lectores. Ariel. https://tinyurl.com/y9qlnszn Duarte-Hueros, J., Duarte-Hueros, A. y Ruano-López, S. (2016). Las descargas de contenidos audiovisuales en Internet entre estudiantes universitarios. Revista Comunicar, 24(48), 49-57. https://doi.org/10.3916/C48-2016-05 Escobar-Ortiz, J. M. E. (2017). Los orígenes del discurso de apropiación social de la ciencia y la tecnología en Colombia. Análisis Político, 30(91), 146-163. https://doi.org/10.15446/anpol.v30n91.70269 
Franklin, B.; Plum, T. (2008). Assessing the Value and Impact of Digital Content. Journal of Library Administration, 48(1), 41-57. https://doi.org/10.1080/01930820802029334

Giraldo-Ramírez, M. E. G. (2008). Metodología para la construcción colaborativa de hipertextos: el caso hipernexus en educación superior. Revista $Q$, 3(5). https://tinyurl.com/y9e6jxgk

Giraldo-Ramírez, M. E. y Álvarez-Cadavid, G. (2009). Una propuesta para entender los conceptos de uso y apropiación. http://200.3.145.35/rid=1PC31T6LD-1QKJ05M-2R7/Conceptos_Usos_Apropiacion\%5B1\%5D.pdf

Gros, B., Garcia, I. y Escofet, A. (2012). Beyond the Net Generation Debate: A Comparison of Digital Learners in Face-toFace and Virtual Universities. International Review of Research in Open \& Distance Learning, 13(4), 190-210.

https://doi.org/10.19173/irrodl.v13i4.1305

Gros, B. y García-Peñalvo, F. J. (2016). Future Trends in the Design Strategies and Technological Affordances of E-Learning. En M. Spector, B. Lockee y M. Childress (Eds.), Learning, Design, and Technology (pp. 1-23). Cham.

https://doi.org/10.1007/978-3-319-17727-4_67-1

Gros, B. y López, M. (2016). Students as co-creators of technology-rich learning activities in higher education. International Journal of Educational Technology in Higher Education, 13(1), 1-13. https://doi.org/10.1186/s41239-016-0026-

$x$

Hilton, J. (2016). Open educational resources and college textbook choices: a review of research on efficacy and perceptions. Educational Technology Research and Development, 64(4), 573-590. https://doi.org/10.1007/s11423-016-

\section{4-9}

Igarza, R. (2011). El libro - pantalla: los contenidos digitales y el futuro de la lectura. En A. Artopoulos (Ed.), La sociedad de las cuatro pantallas. Una mirada Latinoamericana (pp. 81-102). Ariel. https://tinyurl.com/yadgblkp

Jara, 0. (2001). Dilemas y desafíos de la sistematización de experiencias. Centro de Estudios y Publicaciones Alforja. Jenkins, H. (2010). Transmedia Storytelling and Entertainment: An annotated syllabus. Continuum, 24(6), 943-958. https://doi.org/10.1080/10304312.2010.510599

Leal, D. E. (2012). (Aprendiendo sobre) estrategia de contenidos [Entrada de Blog]. https://reaprender.org/blog/2015/04/12/aprendiendo-sobre-estrategia-de-contenidos/

Litwin, E., Maggio, M. y Lipsman, M. (2005). Tecnología en las aulas: las nuevas tecnologías en las prácticas de la enseñanza, casos para el análisis. Amorrortu Editores.

López-Vélez, B. (2005). Actitudes y opiniones de los docentes en relación con la educación en ambientes virtuales. Casos: Universidad Pontificia Bolivariana y Universidad de Antioquia. Íkala, revista de lenguaje y cultura, 10(16), 171-193. https://tinyurl.com/y9jecwbj Luckin, R. (2008). The learner centric ecology of resources: A framework for using technology to scaffold learning. Computers \& Education, 50(2), 449-462. https://doi.org/10.1016/j.compedu.2007.09.018 Ministerio de Educacion Nacional (MEN). (2012). Recursos Educativos Digitales Abiertos - Colombia. MEN http://aprende.colombiaaprende.edu.co/sites/default/files/naspublic/libroreda_0.pdf Reimers, F. M. y Schleicher, A. (2020). Aprendiendo durante la Pandemia: de la disrupción a la innovación. OECD. https://tinyurl.com/y8egkoq8 Rege-Colet, N. M. (2017). From content-centred to learning-centred approaches: shifting educational paradigm in higher education. Journal of Educational Administration and History, 49(1), 72-86. https://doi.org/10.1080/00220620.2017.1252737 Saavedra-Bautista, C., Cuervo-Cómez, W. O. y Mejía-Ortega, I. D. (2017). Producción de contenidos transmedia, una estrategia innovadora - Production of transmedia content, an innovative strategy. Revista cientifica, 1(28), 6-16. Sabelli, N. R. (2011). Aprendiendo con las cuatro pantallas. En A. Artopoulos (Ed.), La sociedad de las cuatro pantallas. Una mirada Latinoamericana (pp. 79-190). Ariel. https://tinyurl.com/yadgblkp

Sanz, J., Dodero, J. M. y Sánchez, S. (2011). Determinando la relevancia de los recursos educativos abiertos a través de la integración de diferentes indicadores de calidad. Revista de Universidad y Sociedad del Conocimiento (RUSC), 8(2), 4660. http://dx.doi.org/10.7238/rusc.v8i2.1031 
Schamer, 0. (2006). Theory U. Leading from the future as it emerges. The social technology of presencing. Fie/notes, 1-13. https://www2.waisman.wisc.edu/naturalsupports/pdfs/summer/Theory.pdf.

Selwyn, N. (2020). Rethinking Teachers' 'Digital Competence' in Light of COVID-19. Schoo/NewsAustralia.

https://tinyurl.com/yarc7ru3

Sevillano-García, M. L. y Vázquez-Cano, E. (2015). The Impact of Digital Mobile Devices in Higher Education. Journal of Educational Technology \& Society, 18(1), 106-118. https://tinyurl.com/y7nrsguh

Stommel, J., Friends, C. y Morris, S. M. (2020). An Open Letter On the Future of Hybrid Pedagogy. En Hybrid Pedagogy. https://hybridpedagogy.org/an-open-letter-on-the-future-of-hybrid-pedagogy/

Urresti, M. (2011). Las cuatro pantallas y las generaciones jóvenes. En A. Artopoulos (Ed.), La sociedad de las cuatro pantallas. Una mirada Latinoamericana (pp. 3-25). Ariel. https://tinyurl.com/yadgblkp

Wiley, D. A. (2002). Connecting learning objects to instructional design theory: A definition, a metaphor, and a taxonomy. En D. A. Wiley (Ed.), The instructional use of learning objects (pp. 3-23). AIT/AECT

https://members.aect.org/publications/InstructionalUseofLearningObjects.pdf 